\title{
Effects of Microstructure Banding on Hydrogen Assisted Fatigue Crack Growth in X65 Pipeline Steels
}

\author{
Joseph A. Ronevich ${ }^{\mathrm{a}^{*}}$, Brian P. Somerday ${ }^{\mathrm{a}}$, Chris W. San Marchi ${ }^{\text {a }}$

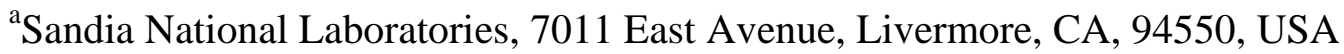

\begin{abstract}
Banded ferrite-pearlite X65 pipeline steel was tested in high pressure hydrogen gas to evaluate the effects of oriented pearlite on hydrogen assisted fatigue crack growth. Test specimens were oriented in the steel pipe such that cracks propagated either parallel or perpendicular to the banded pearlite. The ferrite-pearlite microstructure exhibited orientation dependent behavior in which fatigue crack growth rates were significantly lower for cracks oriented perpendicular to the banded pearlite compared to cracks oriented parallel to the bands. The reduction of hydrogen assisted fatigue crack growth across the banded pearlite is attributed to a combination of cracktip branching and impeded hydrogen diffusion across the banded pearlite.
\end{abstract}

\section{Keywords}

Fatigue crack growth

Carbon steel

Pearlite

\section{Introduction}

For hydrogen fuel delivery from centralized production facilities to point of use, an infrastructure consisting of pipelines provides the most economical method for transporting hydrogen long distances. This concept is not unique as thousands of kilometers of hydrogen pipelines exist today in North America and Europe predominantly for industrial gas producers and petroleum refineries [1-3]. However, in these current hydrogen pipeline systems, the demand is relatively predictable and the operating pressures are modest. As fuel cell vehicles become more abundant, the demand for hydrogen will increase and hydrogen fuel costs can be controlled if the pipeline operating parameters are expanded outside the current envelope. For example, hydrogen fuel pipelines may require higher pressures and may sustain more frequent pressure fluctuations with varying production and demand.

Pipeline steels are susceptible to hydrogen-induced material degradation (e.g., hydrogen embrittlement), and one manifestation is hydrogen assisted fatigue crack growth (HA-FCG). Understanding the degree to which hydrogen accelerates fatigue crack growth is the focus of many studies [4-8]. Recent work [5, 7, 8] has shown that similar fatigue crack growth behavior in hydrogen gas was observed for pipeline steel grades ranging from X52 to X100, which have a wide range of strengths and microstructures. This observation has favorable technology implications since higher strength steels with fatigue performance similar to lower strength steels could result in significant cost savings by allowing pipeline designs with thinner walls. Strength of steel pipes can be managed through control of microstructure, and proper steel selection for hydrogen pipelines requires an understanding of the relationship between microstructure and HA-FCG.

*Corresponding author. Tel.: +1 925294 3115; fax +1 925294 3231; E-mail address: jaronev@ sandia.gov (J.A.

Ronevich)

(C) 2015. This manuscript version is made available under the Elsevier user license

http://www.elsevier.com/open-access/userlicense/1.0/ 
Banded microstructures are common in thicker walled ferrite-pearlite commercial steel pipes in which alternating layers of ferrite and pearlite are elongated in the rolling direction [9]. In these cases, microstructures of steel pipelines are highly anisotropic and mechanical properties can vary as a function of orientation. Fatigue crack growth testing of commercial pipeline steel is often performed using compact tension $(\mathrm{C}(\mathrm{T})$ ) specimens; however, given the modest wall thickness of pipe with respect to the $\mathrm{C}(\mathrm{T})$ specimen dimensions, not all specimen orientations can be extracted from pipe products. As a result, $\mathrm{C}(\mathrm{T})$ specimens are conventionally tested in only one orientation (e.g. C-L) [4-8] which stands for circumferential-longitudinal and measures crack growth rates in the longitudinal direction with load applied in the circumferential direction. However, testing in only one orientation limits the complete evaluation of pipe with banded microstructures, which are known to exhibit orientation dependent fatigue crack growth rates [10-12]. For example, Korda et al. [10-12] performed fatigue crack growth tests in air on banded ferrite-pearlite microstructures and observed a decrease in crack growth rate in a direction perpendicular to the banding (i.e., crack growth in the radial direction) as compared to the longitudinal direction. In the radial direction, the harder regions of pearlite were associated with crack deflection and crack-tip branching, which shielded the crack tip from applied stress and lowered fatigue crack growth rates [11]. The implication of these studies is that a more comprehensive understanding of the relationship between microstructure orientation and fatigue crack growth is required for banded ferrite-pearlite steels in hydrogen gas.

The objective of this study was to evaluate the effects of microstructure banding on fatigue crack growth in high pressure hydrogen gas for modern X65 pipeline steel. Cracks were propagated perpendicular to and parallel to the banded ferrite-pearlite microstructure. Crack growth rates were compared between tests performed in hydrogen gas and air. In both air and hydrogen gas, fatigue crack growth rates were reduced in directions perpendicular to the banded microstructure relative to crack growth rates in directions parallel to the banding. However, the magnitude of this orientation effect was more pronounced in hydrogen gas.

\section{Experimental Procedures}

The material featured in this study was a section of commercial API 5L X65 pipeline with an outside diameter of $508 \mathrm{~mm}$ and a wall thickness of $25.4 \mathrm{~mm}$. Modern processing techniques have greatly reduced microstructural banding in thinner walled pipe; however, thicker walled pipe which is often used in gas pipe-risers can still exhibit banding. The reported chemical composition of the base metal, which was taken from the mill certificate [13], is summarized in Table 1 . The yield strength $(0.2 \%$ offset $)$ and ultimate tensile strength of the pipeline steel were $478 \mathrm{MPa}$ and $564 \mathrm{MPa}$, respectively. These properties were measured from tensile bars in the longitudinal direction and were reported previously [13]. Figure 1a shows the ferrite-pearlite microstructure of the X65 pipeline steel. Microstructural banding is apparent in Fig. 1a in the rolling direction (RD), which is parallel to the pipe longitudinal axis. Figure 1b shows an SEM image of the pearlite colonies and elongated ferrite grains. The microstructure consists of approximately $90 \%$ polygonal ferrite and $10 \%$ pearlite. The average polygonal ferrite grain size was approximately 6 microns as measured from optical micrographs taken of the longitudinalradial plane.

The banded microstructure observed in Fig. 1 is typical of warm-rolled product, which consists of flattened ferrite grains and planar pearlite colonies. Figure $2 \mathrm{a}$ is an isometric representation of three orthogonal pipe orientations, in which the ferrite grains are elongated in the longitudinal 
and circumferential directions. Because the steel was supplied in the form of pipe, the longitudinal (L), circumferential (C), and radial (R) directions are relevant for orientation purposes.

Compact tension $(\mathrm{C}(\mathrm{T}))$ and eccentrically-loaded single edge crack tension (ESE(T)) specimens were extracted from the steel pipe in multiple orientations, i.e., C-L and L-C for C(T) specimens and L-R, L-C, and C-L for ESE(T) specimens. The two letters in the orientation nomenclature (e.g., C-L) refer to the applied loading and crack propagation directions, respectively. Figure $2 \mathrm{~b}$ shows a schematic of the specimen geometries and orientations with respect to the pipe. In Fig. $2 \mathrm{a}$, the dashed lines and associated labels of C-L, L-C, and L-R represent the three crack plane orientations considered in this study. Pipe dimension constraints precluded designing $\mathrm{C}(\mathrm{T})$ specimens in the L-R orientation and required inclusion of the ESE(T) specimen. Tests were performed on the two different geometries, $\mathrm{ESE}(\mathrm{T})$ and $\mathrm{C}(\mathrm{T})$, in the common C-L orientation to assess potential variation in crack growth rates resulting from specimen type.

Table 1 - Chemical Composition (wt.\%) of X65 Pipeline Steel

\begin{tabular}{ccccccccccc}
\hline $\mathrm{Fe}$ & $\mathrm{C}$ & $\mathrm{Si}$ & $\mathrm{Mn}$ & $\mathrm{P}$ & $\mathrm{S}$ & $\mathrm{B}$ & $\mathrm{Cu}$ & $\mathrm{Ni}$ & $\mathrm{Nb}$ & $\mathrm{Ti}$ \\
\hline Bal. & 0.08 & 0.32 & 1.53 & 0.01 & 0.001 & 0.002 & 0.024 & 0.038 & 0.039 & 0.002 \\
\hline
\end{tabular}

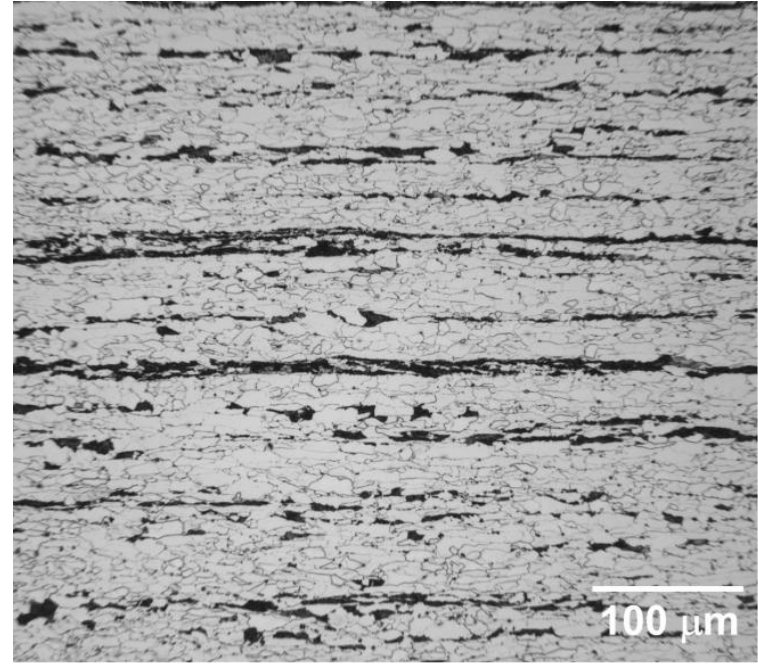

(a)

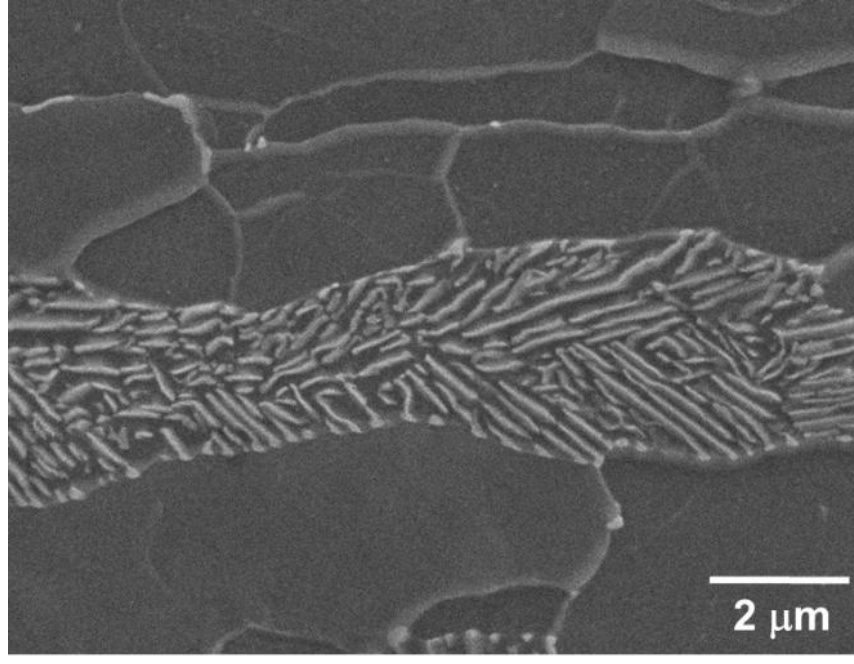

(b)

Figure $1 \quad$ (a) Optical image of X65 pipeline steel showing banded ferrite-pearlite microstructure. (b) SEM image of pearlite constituent and adjacent ferrite grains. In both images, rolling direction is horizontal and the pipe-wall thickness is vertical in the image plane. Etched with $2 \%$ nital. 


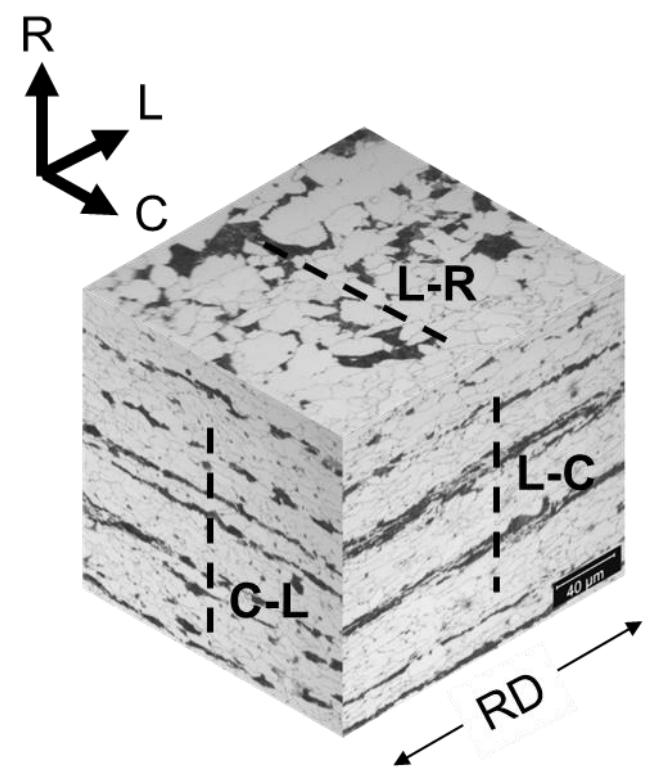

(a)

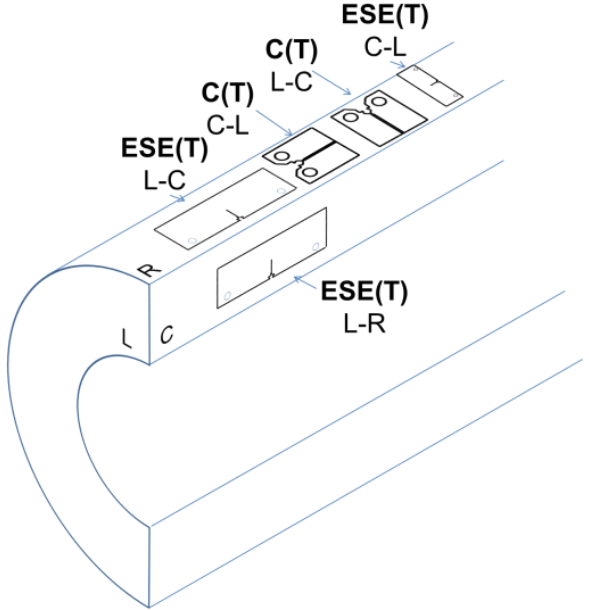

(b)

Figure 2 (a) Isometric view of X65 pipeline steel highlighting microstructure banding in the longitudinal (L) and circumferential (C) directions. (b) Schematic of C(T) and $\mathrm{ESE}(\mathrm{T})$ specimen orientations relative to pipe. The dashed lines and associated labels of C-L, L-C, and L-R in (a) indicate the crack plane orientations relative to the steel pipe microstructure.

Specimen design and fatigue crack growth testing followed ASTM Standard E647-05 [14]. All $\mathrm{C}(\mathrm{T})$ specimens were designed with width $(\mathrm{W})=26.4 \mathrm{~mm}$ and precrack-starter notch length-towidth ratio $(\mathrm{a} / \mathrm{W})=0.2$. The thickness $(\mathrm{B})$ of the $\mathrm{C}(\mathrm{T})$ specimens was $12.7 \mathrm{~mm}$. Side grooves in the $\mathrm{C}(\mathrm{T})$ specimens reduced the net thickness $\left(\mathrm{B}_{\mathrm{n}}\right)$ to $11.2 \mathrm{~mm}$ in the crack plane. $\mathrm{ESE}(\mathrm{T})$ specimens were designed with $\mathrm{W}=19.0 \mathrm{~mm}$ and $\mathrm{B}=4.76 \mathrm{~mm}$ for the $\mathrm{L}-\mathrm{R}$ and $\mathrm{L}-\mathrm{C}$ orientations and $\mathrm{W}=12.7 \mathrm{~mm}$ and $\mathrm{B}=3.18 \mathrm{~mm}$ for the $\mathrm{C}-\mathrm{L}$ orientation. The $\mathrm{ESE}(\mathrm{T})$ specimens had a consistent precrack-starter notch length-to-width ratio $(\mathrm{a} / \mathrm{W}=0.2)$ and were designed without side grooves. Prior to precracking, specimens were ultrasonically cleaned in isopropyl alcohol. Precracking was performed in air under the following conditions: load-cycle frequency $=15 \mathrm{~Hz}$, final maximum stress intensity factor $\left(\mathrm{K}_{\max }\right)=13.2 \mathrm{MPa} \mathrm{m}{ }^{1 / 2}$, and $\mathrm{K}_{\min } / \mathrm{K}_{\max }($ load ratio, $\mathrm{R})=$ 0.5. ${ }^{1}$ The final precrack lengths, a/W, ranged from 0.25 to 0.29 .

Fatigue crack growth testing was performed on $\mathrm{C}(\mathrm{T})$ and $\mathrm{ESE}(\mathrm{T})$ specimens in high-purity $(99.9999 \%)$ hydrogen gas at room temperature (295 K). Triplicate tests were performed on C-L and L-C oriented specimens and duplicate on L-R oriented specimens tested in hydrogen gas. A servo-hydraulic load frame equipped with a custom built pressure vessel allowed concurrent mechanical loading and hydrogen gas exposure of the test specimens. One key feature of the pressure vessel was spring energized Teflon ${ }^{\circledR}$ U-cup seals, which prevented gas leaks between the pull rod and bottom cover bore while allowing for dynamic pull rod motion. After the pressure vessel was assembled with the test specimen in the load train, residual air was removed

\footnotetext{
${ }^{1}$ Two of the $\mathrm{C}(\mathrm{T}) \mathrm{C}-\mathrm{L}$ specimens were precracked to a final $\mathrm{K}_{\max }$ of $7.7 \mathrm{MPa} \mathrm{m}^{1 / 2}$ at $\mathrm{R}=0.1$, however all subsequent samples were precracked as stated above.
} 
from the gas chamber by applying 4 purge cycles with high purity helium (13.8 MPa pressure) followed by an evacuation cycle. Four successive purges with high purity hydrogen gas (13.8 MPa pressure) were then applied prior to final filling to the test pressure. The test pressure was selected as $21 \mathrm{MPa}$, since this pressure is identified as an upper bound specified for hydrogen pipelines in the ASME B31.12 Hydrogen Piping and Pipelines Code [15]. Once the test pressure was attained, a minimum $48 \mathrm{~h}$ period was necessary to allow the internal load cell output to reach saturation, since the strain gauges were susceptible to drift in hydrogen gas during this time. As the chamber was filled with gas, the specimens did not sustain loads since a secondary balance chamber in the pressure vessel was concurrently filled with gas to ensure that net forces on the pull rod were zero.

Constant load amplitude fatigue crack growth tests were performed on C(T) and ESE(T) specimens in high pressure hydrogen gas at a load-cycle frequency of $1 \mathrm{~Hz}$ and a load ratio, $\mathrm{R}$, of 0.5. C(T) specimens were tested in the C-L and L-C orientations and $\operatorname{ESE}(\mathrm{T})$ specimens were tested in the L-R orientation. During operation of projected hydrogen fuel pipelines, the pressure is expected to fluctuate as low as $50 \%$ of its maximum level, which is the justification for the selection of $\mathrm{R}=0.5$. Crack growth rates of pipeline steels are sensitive to test frequency in hydrogen gas, with lower frequencies resulting in higher fatigue crack growth rates [7, 16], however, testing at lower frequencies often requires extended durations. Therefore, the test frequency of $1 \mathrm{~Hz}$ was selected to balance reasonable test durations with measuring upper bound crack growth rates. In the constant load amplitude format, the stress intensity factor range, $\Delta \mathrm{K}$, increases as the crack grows. Selection of the load amplitude (i.e., initial $\Delta K$ ) was a compromise between acquiring data over a wide $\Delta \mathrm{K}$ range and test duration, since extending the $\Delta \mathrm{K}$ range to lower values requires exponentially longer times to achieve measureable crack extension. A triangular loading wave form was applied with internal load cell feedback, which ensures that the minimum and maximum loads sustained by the specimen are achieved despite friction forces from the U-cup seals. For $\mathrm{C}(\mathrm{T})$ specimens the crack mouth opening displacement was measured using a linear variable differential transformer (LVDT) attached to the front face. Negligible drift was observed in the LVDT output signal during exposure to high pressure hydrogen gas. For the $\mathrm{ESE}(\mathrm{T})$ specimens, a strain gauge-based extensometer was attached to the specimen front face to measure crack mouth opening displacement. This strain gauge-based extensometer displayed output signal drift comparable to the internal load cell during exposure to hydrogen gas, which saturated within $48 \mathrm{~h}$. For both specimen geometries, crack extension was calculated from the unloading compliance technique. Load, crack opening displacement, and crack length data were recorded at crack extension intervals of $0.1 \mathrm{~mm}$.

The incremental polynomial method [17] was applied to calculate the crack growth increment per load cycle $(\mathrm{da} / \mathrm{dN})$ as a function of $\Delta \mathrm{K}$ for fatigue crack growth tests. Following the completion of fatigue testing, specimens were soaked in liquid nitrogen for a minimum of 10 minutes and then fractured open. Three distinct crack-extension regions were readily apparent on the fracture surfaces for specimens tested in hydrogen gas: precrack, crack propagation in hydrogen, and overload in air at liquid nitrogen temperature. In order to visually delineate the different crack-extension regions for specimens tested in air, specimens were first heat tinted at $275^{\circ} \mathrm{C}$ for $30 \mathrm{~min}$, and then soaked in liquid nitrogen and fractured open. Initial and final crack lengths were measured optically from the fracture surfaces and were used to correct crack lengths calculated from the unloading compliance method. The initial and final crack lengths measured optically were used as fixed bounds, and the crack lengths measured by the unloading 
compliance method were linearly corrected to these end points. Typically, measured initial crack lengths were within $10 \%$ of the compliance calculated value for $\operatorname{ESE}(\mathrm{T})$ specimens and within $20 \%$ for C(T) specimens. Values for the final crack lengths were within $1 \%$ for both specimen geometries.

After completion of selected tests in hydrogen gas, samples of the test gas were collected and subsequently analyzed by a commercial laboratory for impurities such as oxygen and water vapor, since oxygen-bearing species can inhibit hydrogen assisted fatigue crack growth [16]. Impurity contents did not exceed $4 \mathrm{vppm} \mathrm{O}_{2}$ and $9 \mathrm{vppm} \mathrm{H}_{2} \mathrm{O}$. It is not expected that these levels of impurities significantly affected the results.

In addition to fatigue tests performed in hydrogen gas, companion tests were performed in air at room temperature $(295 \mathrm{~K})$. Test parameters in air were identical to those in hydrogen gas except that load-cycle frequency was increased to $10 \mathrm{~Hz}$. C(T) specimens were tested in the $\mathrm{C}-\mathrm{L}$ and L-C orientations and ESE(T) specimens were tested in L-C, C-L, and L-R orientations. Relative humidity for tests in air was between 10 and 50\%. Previous work [16] on low strength pipelines tested in air at 30-60\% humidity levels exhibited similar fatigue curves as pipeline tested in nitrogen [4] which would have humidity levels likely less than $1 \%$. Therefore, it is not anticipated that the humidity levels tested in this current work will have a significant effect on these lower strength pipeline steels.

Microscopy was performed on fatigue crack growth specimens in either light optical or scanning electron microscopes. The broad surface perpendicular to the crack plane on select specimens (without side grooves) were polished and etched prior to fracturing open to allow examination of crack path with respect to the microstructure. Fracture surfaces of select specimens were also examined in a scanning electron microscope.

\section{Results}

The fatigue crack growth rate (FCGR) relationships, da/dN vs. $\Delta \mathrm{K}$, measured for $\mathrm{X} 65$ pipeline steel display expected trends in hydrogen gas and air. Figure 3 presents da/dN vs. $\Delta \mathrm{K}$ curves measured in $21 \mathrm{MPa}$ hydrogen gas for the C-L, L-C, and L-R orientations. Duplicate or triplicate tests are shown in Fig. 3 for the three orientations tested in hydrogen gas. For comparison, da/dN vs. $\Delta \mathrm{K}$ relationships in air are included for the C-L, L-C, and L-R orientations. For all orientations in air, da/dN vs. $\Delta \mathrm{K}$ is approximately linear in the plot with logarithmic axes, typical for stage II fatigue crack growth. Single tests were run for fatigue tests in air. For the tests performed in $21 \mathrm{MPa}$ hydrogen gas, HA-FCG is manifested through higher crack growth rates compared to those in air. Consistent with previous measurements of HA-FCG for lower-strength ferritic steels, the da/dN vs. $\Delta \mathrm{K}$ relationships exhibit three characteristic regimes [4-8]. At low $\Delta \mathrm{K}$ ranges (less than $\sim 10 \mathrm{MPa}{ }^{1 / 2}$ ), the FCGR in hydrogen gas converges with crack growth rates in air. This trend is most prevalent for the L-R oriented specimens. At intermediate $\Delta \mathrm{K}$ ranges (between 10 and $15 \mathrm{MPa} \mathrm{m}^{1 / 2}$ ) the crack growth rate in hydrogen accelerates above growth rates in air. Above $\Delta \mathrm{K} \sim 15 \mathrm{MPa} \mathrm{m}^{1 / 2}$, the crack growth rates in hydrogen exceed those in air by over an order of magnitude. 
The da/dN vs. $\Delta \mathrm{K}$ relationships measured for X65 pipeline steel in both hydrogen gas and air were sensitive to crack plane orientation relative to the steel pipe. As illustrated in Fig. 3, the FCGR depended modestly on crack plane orientation throughout the entire $\Delta \mathrm{K}$ range for tests in air. The highest FCGR was measured in the C-L orientation, followed by the L-C and L-R orientations. In hydrogen gas, comparison of da/dN vs. $\Delta \mathrm{K}$ for the three crack plane orientations indicates a substantial difference in crack growth rates for $\Delta \mathrm{K}<15 \mathrm{MPa} \mathrm{m}^{1 / 2}$, in which FCGR was significantly lower in the L-R orientation compared to the C-L and L-C orientations. In contrast, the L-C orientation exhibited only slightly lower FCGR than the C-L orientation. For $\Delta \mathrm{K}>15 \mathrm{MPa} \mathrm{m}{ }^{1 / 2}$, crack growth rates were similar for the $\mathrm{C}-\mathrm{L}$ and $\mathrm{L}-\mathrm{C}$ orientations, although these FCGR remained a factor of two higher compared to the L-R orientation. The collective results in hydrogen gas and air indicate that FCGR is orientation dependent, and the effects of orientation appear magnified in hydrogen gas.

In order to identify possible specimen geometry effects, $\mathrm{ESE}(\mathrm{T})$ and $\mathrm{C}(\mathrm{T})$ specimens were both tested in the same orientation (i.e. C-L) in air. As shown in Fig. 3, da/dN vs. $\Delta \mathrm{K}$ relationships are nearly the same between $\mathrm{C}(\mathrm{T}) \mathrm{C}-\mathrm{L}$ and $\mathrm{ESE}(\mathrm{T}) \mathrm{C}-\mathrm{L}$ specimens, which validates that specimen geometry effects are negligible and results from the two specimen types can be directly compared.

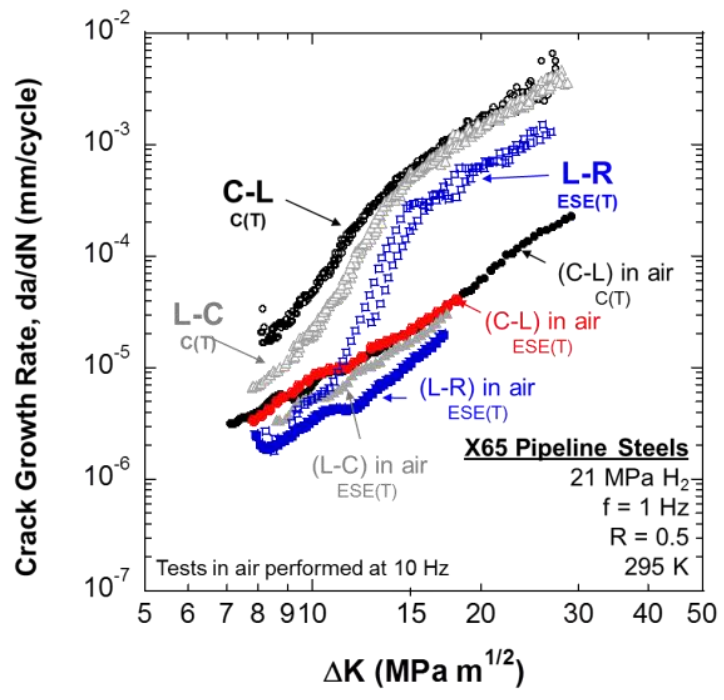

Figure 3 Fatigue crack growth rate relationships (da/dN vs. $\Delta \mathrm{K})$ for $\mathrm{C}(\mathrm{T})$ and $\mathrm{ESE}(\mathrm{T})$ specimens of X65 pipeline steel in three orientations (C-L, L-C, and L-R) and two environments (21 MPa hydrogen gas and air).

Scanning electron microscopy (SEM) and light optical microscopy were applied to fracture surfaces and crack profiles to identify features that explain observed differences in FCGR between the different orientations. The fracture surfaces were examined for the three specimen orientations tested in $21 \mathrm{MPa}$ hydrogen gas, and the SEM images are shown in Fig. 4. The micrographs represent locations corresponding to $\Delta \mathrm{K} \sim 12 \mathrm{MPa} \mathrm{m}^{1 / 2}$, and in all images crack growth is from bottom to top. Fracture surfaces exhibit predominantly transgranular crack-path features with a small fraction of intergranular facets; however, the most notable feature in the 
micrographs is the orientation of secondary microcracks appearing normal to the primary crack plane. In Figs. 4a (C-L orientation) and 4b (L-C orientation), microcracks are aligned parallel to the primary crack growth direction. In contrast, Fig. 4c (L-R orientation) shows secondary microcracks oriented perpendicular to the primary crack growth direction (and parallel to the crack front). Tests in air exhibited different fracture surface features compared to tests in hydrogen gas. Figures 5a, 5b, and 5c show the fracture surfaces from tests in air of the C-L, L-C, and L-R orientations, respectively, at locations corresponding to $\Delta \mathrm{K} \sim 12 \mathrm{MPa} \mathrm{m}^{1 / 2}$. Fracture surfaces consist of transgranular features with negligible intergranular facets. It is noted that transgranular fracture is distinctly different in air compared to hydrogen gas as shown in Figs. 6a and 6b, i.e., transgranular fracture in air (Fig. 6a) exhibits striations perpendicular to the crack growth direction whereas faceted features are observed for the transgranular fracture produced in hydrogen gas (Fig. 6b). Additionally, in Figs. 5a (C-L orientation) and 5b (L-C orientation), negligible microcracks are observed parallel to the crack growth direction, in contrast to the tests performed in hydrogen gas (Figs. 4a and 4b, respectively). However, microcracks are observed perpendicular to the crack growth direction in Fig. 5c (L-R orientation) for tests in air, analogous to features in hydrogen gas for this crack growth orientation (Fig. 4c).

In order to examine details of secondary microcracks, an L-R oriented specimen was not fractured open following fatigue testing in hydrogen gas, and the broad face was polished and etched to reveal the crack profile relative to the microstructure. Figure 7 shows images of this L$\mathrm{R}$ oriented specimen in which the primary crack propagation direction is perpendicular to the banded ferrite-pearlite microstructure. The primary crack propagated from left to right in Figs. 7a and $7 \mathrm{~b}$ and secondary microcracks are observed branching from the primary crack plane. These crack branches in Fig. 7 are revealed on fracture surfaces as secondary microcracks perpendicular to the crack growth direction (Fig. 4c and Fig. 5c). Therefore, examination of the fracture surfaces shows that crack branching is present in both testing environments (e.g., air and hydrogen gas) in the L-R oriented specimens. The effects of microcracking and orientation on fatigue crack growth rates are elaborated in the following section.

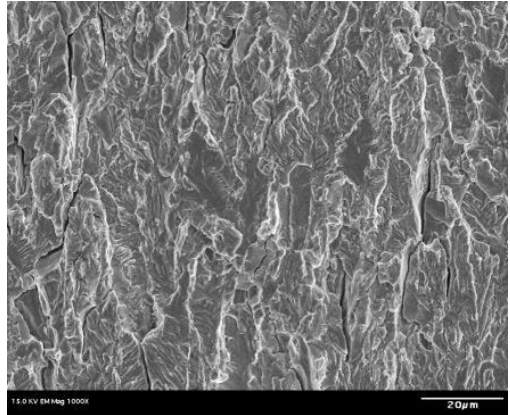

(a)

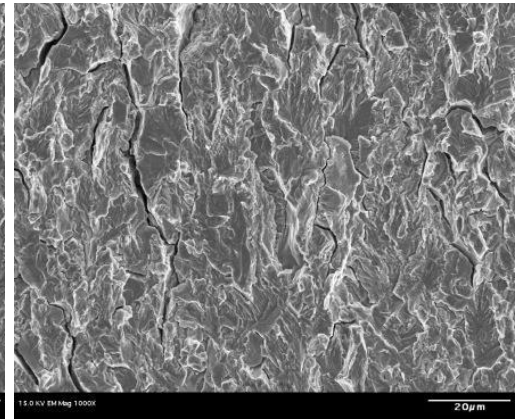

(b)

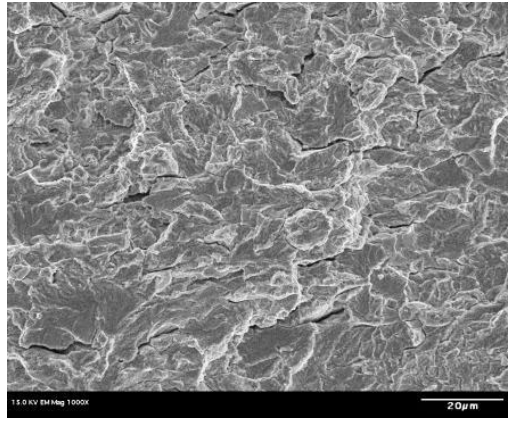

(c)

Figure 4 SEM images from fracture surfaces of $\mathrm{X} 65$ pipeline steel tested in $21 \mathrm{MPa} \mathrm{H}_{2}$ at $\Delta \mathrm{K} \sim 12 \mathrm{MPa} \mathrm{m}^{1 / 2}$ for (a) C-L orientation, (b) L-C orientation, (c) L-R orientation. Crack growth direction is from bottom to top. 


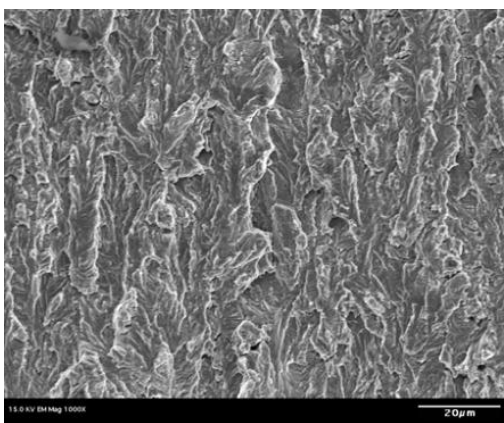

(a)

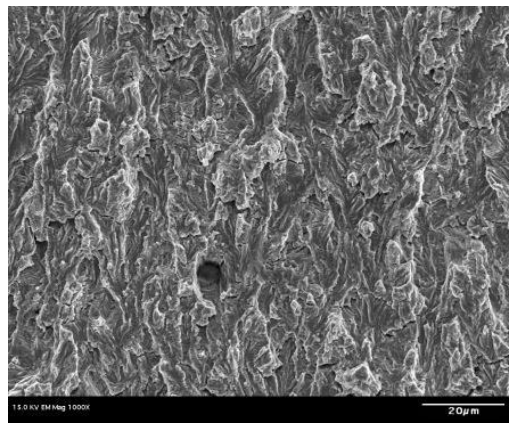

(b)

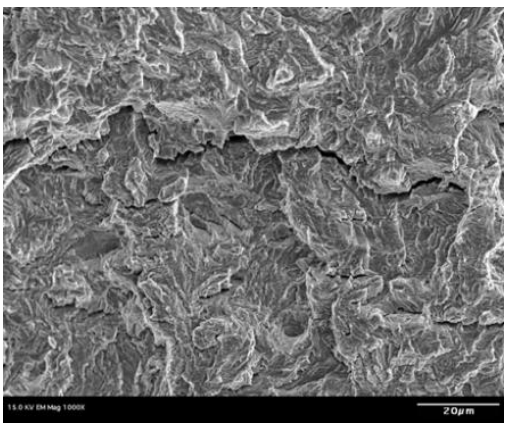

(c)

Figure 5 SEM images from fracture surfaces of X65 pipeline steel tested in air at $\Delta \mathrm{K} \sim$ $12 \mathrm{MPa} \mathrm{m}^{1 / 2}$ for (a) C-L orientation, (b) L-C orientation, (c) L-R orientation. Crack growth direction is from bottom to top.

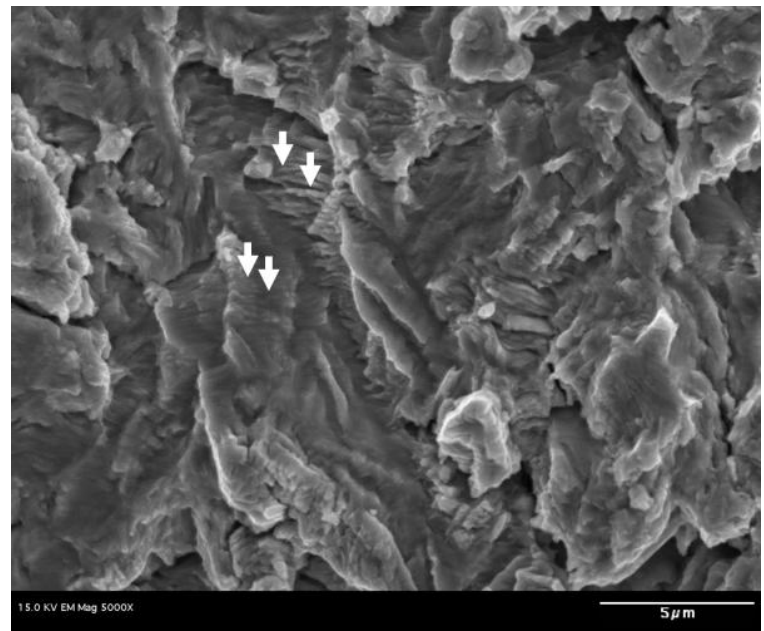

(a)

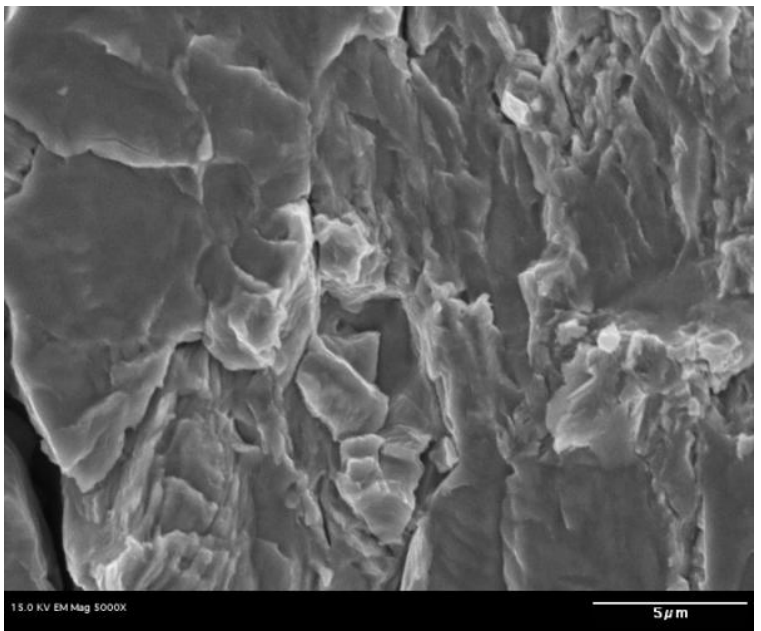

(b)

Figure $6 \quad \mathrm{SEM}$ images from fracture surfaces of $\mathrm{X} 65$ pipeline steel at $\Delta \mathrm{K} \sim 12 \mathrm{MPa} \mathrm{m}^{1 / 2}$ in L-C orientation tested in (a) air and (b) $21 \mathrm{MPa}$ hydrogen gas. White arrows in (a) identify fatigue striations perpendicular to crack growth direction. 


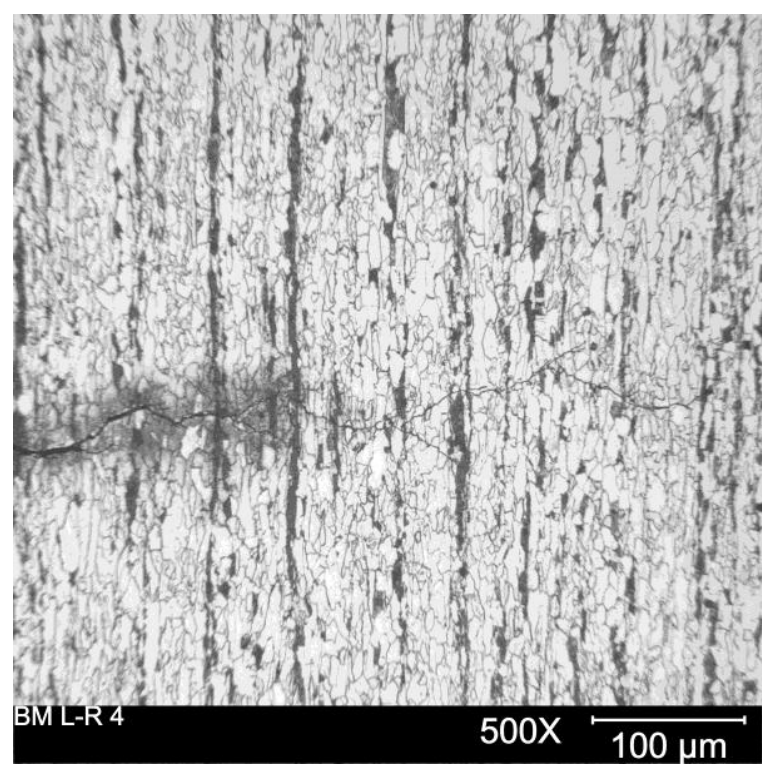

(a)

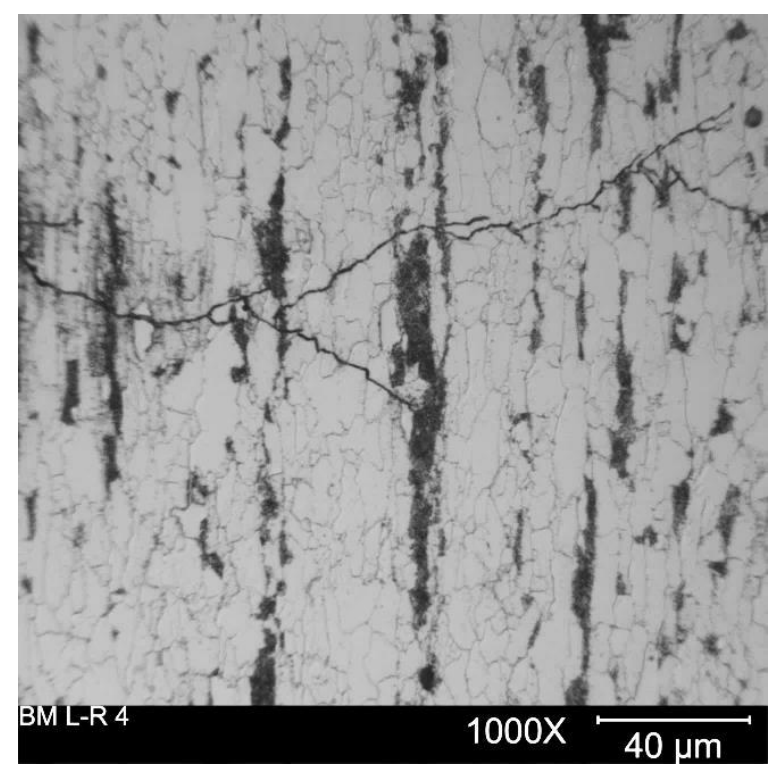

(b)

Figure 7 Optical image of fatigue crack propagating in the L-R orientation in $21 \mathrm{MPa}$ hydrogen gas. (a) low magnification, (b) higher magnification showing a tortuous crack path with crack branching. Images represent crack growth at $\Delta \mathrm{K} \sim 26$ $\mathrm{MPa} \mathrm{m}^{1 / 2}$.

\section{Discussion}

Fatigue crack growth rates are dependent on the orientation of cracks relative to the banded ferrite-pearlite microstructure in both hydrogen gas and air. Figure $2 \mathrm{a}$ shows that the microstructure is anisotropic and has elongated grains in the longitudinal and circumferential directions from the controlled rolling process. As a consequence of the anisotropy, the crack plane in L-R oriented specimens intersects a different pattern of microstructural features compared to the crack planes in L-C or C-L oriented specimens. Specifically, cracks propagating in the L-R orientation encounter alternating planes of ferrite and pearlite, whereas cracks in the L-C and C-L orientations propagate along bands of ferrite and pearlite. Figure 3 shows that orientation has distinct effects on fatigue crack growth rates, in particular for the L-R orientation, in which cracks propagating perpendicular to the banded microstructure exhibit the lowest crack growth rates. This is consistent with previous work in air $[10,11]$ that demonstrated lower crack growth rates for cracks propagating perpendicular to banded pearlite.

In order to assess the effects of banded microstructures on fatigue crack growth rates in a more absolute sense, data for the banded X65 steel in the present work are compared to HA-FCG data for X52, X60, X70, and X80 steels [18-21], which did not possess banded microstructures. Figure 8 shows da/dN vs $\Delta \mathrm{K}$ curves for the present $\mathrm{X} 65$ steel in the C-L, L-C, and L-R orientations. For comparison, results are also shown in Fig. 8 for X60 and X80 steels tested in 21 MPa hydrogen gas [20,21] as well as two X70 steels (A and B) and two X52 steels (vintage and modern) tested in $34 \mathrm{MPa}$ hydrogen gas $[18,19]$. It was reported $[18,19]$ that none of the X52 or 
X70 steels exhibited significant microstructural banding. Similarly, optical images did not reveal microstructure banding in the X60 and X80 steels [20, 21]. These alternate pipeline steels were composed of a wide range of microstructures, i.e., $90 \%$ polygonal ferrite (PF) and $10 \%$ acicular ferrite $(\mathrm{AF})$ in $\mathrm{X} 70 \mathrm{~A}, 90 \% \mathrm{PF}$ and $10 \%$ bainite in $\mathrm{X} 70 \mathrm{~B}, 70 \% \mathrm{PF}$ and $30 \%$ pearlite in vintage $\mathrm{X} 52$, and $90 \% \mathrm{PF}$ and $10 \% \mathrm{AF}$ in modern X52 $[18,19]$. The X60 was $100 \% \mathrm{PF}$ and the X80 was $90 \% \mathrm{PF}$ and $10 \%$ coarse AF [21]. The banded X65 microstructure in the present study consisted of $90 \% \mathrm{PF}$ and $10 \%$ pearlite. The X52, X60, X70, and X80 steels were tested in the C-L orientation and at the same frequency $(1 \mathrm{~Hz})$ and $\mathrm{R}$ ratio $(0.5)$ as the current study; however, the X52 and X70 steels were tested at higher gas pressure (e.g., $34 \mathrm{MPa}$ ). As shown in Fig. 8, the pipeline steels without microstructure banding exhibit crack growth rates in hydrogen gas comparable to those for X65 in the C-L and L-C orientations. Although some scatter is observed among tests in the C-L orientation, it is clear that data for the X65 L-R orientation fall outside of these characteristic crack growth rates for the C-L orientation, confirming that the banded microstructure has an absolute effect in reducing HA-FCG when cracks propagate normal to the ferrite-pearlite bands.

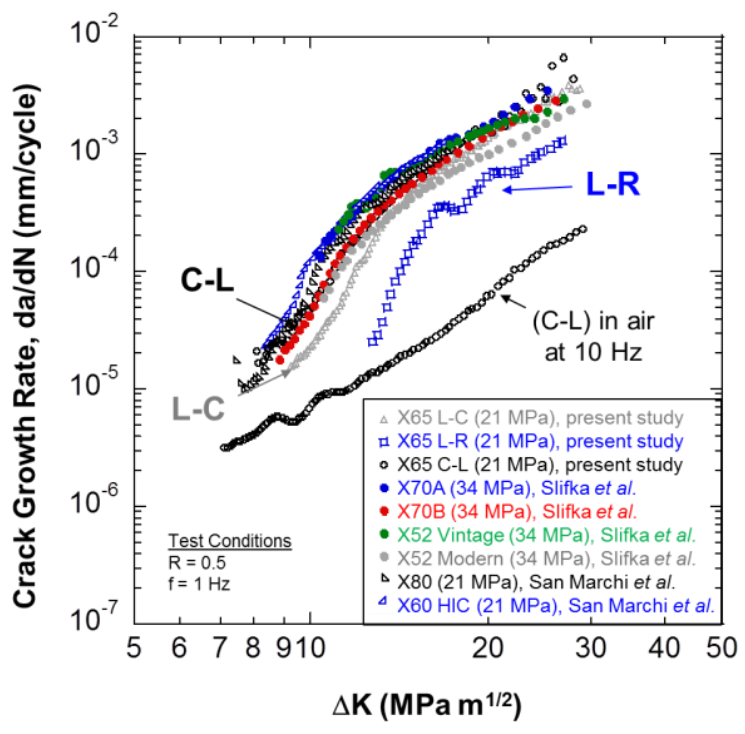

Figure 8 Fatigue crack growth rate relationships (da/dN vs $\Delta \mathrm{K}$ ) for X65 in the C-L, L-C, and L-R orientations compared to data for X80 and X60 HIC (21 MPa hydrogen gas $[20,21]$ ) and for X70A, X70B, X52 vintage, and X52 modern steels (34 MPa hydrogen gas $[18,19])$. All tests were conducted at $R=0.5$ and frequency of $1 \mathrm{~Hz}$. Test specimens from [18-21] were in the C-L orientation. The X65 C-L orientation tested in air at $10 \mathrm{~Hz}$ is shown for comparison.

Differences in crack growth rates for the three crack plane orientations in the present study were quantified by tabulating da/dN values from Fig. 3 at select $\Delta \mathrm{K}$ levels of $10,12,15$ and 20 $\mathrm{MPa} \mathrm{m}^{1 / 2}$ (Table 2). Ratios of da/dN were calculated to highlight the effects of environment on relative crack growth rates for particular orientations. Note: ratios were not reported for air data at $\Delta \mathrm{K}=20 \mathrm{MPa} \mathrm{m}^{1 / 2}$ because data was not collected at $\Delta \mathrm{K}$ levels greater than approximately $17 \mathrm{MPa} \mathrm{m}^{1 / 2}$ for the L-R and L-C orientations. For example, the relative crack growth rate perpendicular to the microstructure banding is reported as the da/dN ratio for the C-L and L-R orientations ([da/dN $\left.\mathrm{C}-\mathrm{L}] /\left[\mathrm{da} / \mathrm{dN}_{\mathrm{L}-\mathrm{R}}\right]\right)$ in Table 2 . In addition, the relative crack growth rate parallel 
to the microstructure banding is listed as the $\mathrm{da} / \mathrm{dN}$ ratio for the $\mathrm{C}-\mathrm{L}$ and $\mathrm{L}-\mathrm{C}$ orientations ([da/dN $\left.\left.\mathrm{C}_{\mathrm{C}-\mathrm{L}}\right] /\left[\mathrm{da} / \mathrm{dN}_{\mathrm{L}-\mathrm{C}}\right]\right)$. Considering relative crack growth rates perpendicular to the microstructure banding, the ratio $\left[\mathrm{da} / \mathrm{dN}_{\mathrm{C}-\mathrm{L}}\right] /\left[\mathrm{da} / \mathrm{dN}_{\mathrm{L}-\mathrm{R}}\right]$ is approximately 2 in air at $\Delta \mathrm{K}=10 \mathrm{MPa}$ $\mathrm{m}^{1 / 2}$, indicating that the FCGR in the L-R orientation is two times slower than the FCGR in the $\mathrm{C}-\mathrm{L}$ orientation. When the environment is hydrogen gas, this $\left[\mathrm{da} / \mathrm{dN}_{\mathrm{C}-\mathrm{L}}\right] /\left[\mathrm{da} / \mathrm{dN}_{\mathrm{L}-\mathrm{R}}\right]$ ratio is 8.9 , demonstrating that relative FCGR is nearly an order of magnitude slower in the L-R orientation compared to the $\mathrm{C}$-L orientation. At higher $\Delta \mathrm{K}$ levels the ratio of crack growth rates between the $\mathrm{C}-\mathrm{L}$ and L-R orientations decreases to approximately 2 for both air and hydrogen gas. A comparison of crack growth rates in the $\mathrm{C}-\mathrm{L}$ and $\mathrm{L}-\mathrm{C}$ orientations reveals that crack growth rate ratios are similar regardless of $\Delta \mathrm{K}$ range and environment, and the ratio of $\left[\mathrm{da} / \mathrm{dN}_{\mathrm{C}-\mathrm{L}}\right] /\left[\mathrm{da} / \mathrm{dN}_{\mathrm{L}-\mathrm{C}}\right]$ is consistently between 1.2 and 2. Collectively, the crack growth rate ratios emphasize that similar relative FCGRs were measured for cracks propagating parallel to the banded microstructure, but relative FCGR was significantly reduced for cracks propagating perpendicular to the banded microstructure, particularly in hydrogen gas.

Table 2 Absolute and Relative Crack Growth Rates at Select $\Delta \mathrm{K}$ values for C-L, L-C, and L-R Oriented Specimens in Air and Hydrogen Gas

\begin{tabular}{|c|c|c|c|c|}
\hline \multirow[b]{2}{*}{ Orientation (Environment) } & \multicolumn{4}{|c|}{ Crack growth rate, da/dN $\left(\times 10^{-5} \mathrm{~mm} /\right.$ cycle $)$ at select $\Delta \mathrm{K}$} \\
\hline & $10 \mathrm{MPa} \mathrm{m}^{1 / 2}$ & $12 \mathrm{MPa} \mathrm{m}^{1 / 2}$ & $15 \mathrm{MPa} \mathrm{m}^{1 / 2}$ & $20 \mathrm{MPa} \mathrm{m}^{1 / 2}$ \\
\hline C-L (Air) & 0.745 & 1.13 & 2.14 & 6.37 \\
\hline L-R (Air) & 0.350 & 0.447 & 1.15 & $N / A^{*}$ \\
\hline L-C (Air) & 0.543 & 0.927 & 1.73 & $N / A^{*}$ \\
\hline $\begin{array}{c}\text { Perpendicular } \\
\text { Ratio in Air, } \frac{d a / d N_{C-L}}{d a / d N_{L-R}}\end{array}$ & 2.1 & 2.5 & 1.9 & $N / A^{*}$ \\
\hline $\begin{array}{c}\text { Parallel } \\
\text { Ratio in Air, } \frac{d a / d N_{C-L}}{d a / d N_{L-C}}\end{array}$ & 1.4 & 1.2 & 1.2 & $N / A^{*}$ \\
\hline C-L $\left(\mathbf{H}_{2}\right)$ & 4.60 & 17.6 & 61.5 & 159 \\
\hline L-R $\left(\mathrm{H}_{2}\right)$ & 0.519 & 2.16 & 29.0 & 69.4 \\
\hline L-C $\left(\mathrm{H}_{2}\right)$ & 2.30 & 11.6 & 51.5 & 139 \\
\hline $\begin{array}{c}\text { Perpendicular } \\
\text { Ratio in } \mathrm{H}_{2}, \frac{d a / d N_{C-L}}{d a / d N_{L-R}}\end{array}$ & 8.9 & 8.1 & 2.1 & 2.3 \\
\hline $\begin{array}{c}\text { Parallel } \\
\text { Ratio in } \mathrm{H}_{2}, \frac{d a / d N_{C-L}}{d a / d N_{L-C}}\end{array}$ & 2.0 & 1.5 & 1.2 & 1.1 \\
\hline
\end{tabular}

$* \mathrm{~N} / \mathrm{A}=$ Not Applicable. Data was not obtained at this $\Delta \mathrm{K}$ range.

Hydrogen embrittlement in the form of hydrogen assisted fatigue crack growth requires several elements to activate; for example, critical magnitudes of crack-tip driving forces (e.g., threshold levels of crack-tip stress and plastic strain accumulation) and sufficient supply of hydrogen to lower cracking resistance at susceptible microstructure sites. Consequently, factors that reduce crack-tip driving forces or impede hydrogen supply will diminish HA-FCG [16]. Fracture surfaces from the L-R oriented specimens (Figs. 4c and 5c) show secondary microcracks that are 
indicative of crack branching in both test environments, air and hydrogen gas. Crack-tip branching has been observed in ferrite-pearlite steels tested in air [10-12] and attributed to harder constituents such as pearlite or cementite, which deflect or in some cases arrest the crack. It has been reported $[10,11]$ that crack branching induces a shielding effect, reducing the local cracktip driving force. For the current tests on X65 pipeline steel in air, fracture surfaces from the L-C and C-L orientations did not reveal crack branching in contrast to fracture surfaces from the L-R orientation, which may account for the lower fatigue crack growth rates measured in the L-R orientation. Fracture surfaces of L-C and C-L specimens tested in hydrogen gas do exhibit secondary microcracks; however, these do not reflect crack branching but rather represent delaminations that form along the microstructure bands and thus appear as secondary microcracks parallel to the crack growth direction [23, 24]. Previous work in air [10, 11] demonstrated that reduced fatigue crack growth rates associated with crack-tip branching were particularly prevalent for fatigue cracks propagating perpendicular to banded pearlite. While it is reasonable to presume that crack branching contributes to reduced FCGR in L-R oriented specimens relative to $\mathrm{C}$-L oriented specimens in both air and hydrogen gas, the notably higher $\left[\mathrm{da} / \mathrm{dN}_{\mathrm{C}-\mathrm{L}}\right] /\left[\mathrm{da} / \mathrm{dN}_{\mathrm{L}-\mathrm{R}}\right]$ ratio in hydrogen gas compared to air suggests that crack branching is compounded by additional factors in hydrogen gas.

The significant difference between $\mathrm{da} / \mathrm{dN}_{\mathrm{C}-\mathrm{L}}$ and $\mathrm{da} / \mathrm{dN}_{\mathrm{L}-\mathrm{R}}$ at $\Delta \mathrm{K}<15 \mathrm{MPa} \mathrm{m} \mathrm{m}^{1 / 2}$ may be attributed to banded pearlite impeding hydrogen transport to the embrittlement site. Hydrogen permeation studies [25] performed on banded ferrite-pearlite 4130 steel microstructures showed that effective hydrogen diffusivity was lowest in the short transverse direction (e.g., the radial, $\mathrm{R}$, direction for this study) and highest in the longitudinal direction (e.g., L direction for this study). Diffusivity values in the transverse (or circumferential, C) direction are intermediate to values for the short transverse and longitudinal directions (e.g., R and L directions, respectively) [25]. Additionally, comparison of effective hydrogen diffusivity in a banded vs. randomly distributed pearlite microstructure revealed the predominant diffusion path to be ferrite or ferritepearlite interfaces [25]. In Lee et al. [26], hydrogen uptake was most limited when permeation was confined to the direction perpendicular to the banded ferrite-pearlite microstructures, supporting the concept that pearlite restricts hydrogen diffusion. In work by Cialone and Holbrook [27], fatigue crack growth tests in $7 \mathrm{MPa}$ hydrogen gas were performed on commercially pure iron (ferrite) and 1080 steel (pearlite). HA-FCG was significantly lower in the pearlitic 1080 steel, which was attributed to lower hydrogen diffusivity in the pearlite compared to the fully ferritic microstructure. These studies lead to the following two interpretations: 1) hydrogen transport through pearlite is notably lower than hydrogen transport through ferrite, and 2) the difference in hydrogen transport in pearlite vs. ferrite can affect fatigue crack growth rates in ferrite-pearlite microstructures. In the banded ferrite-pearlite microstructure for the current X65 pipeline steel, effective hydrogen diffusivity is lowered as it diffuses through layers of pearlite in L-R oriented specimens, which reduces the rate of hydrogen supply to the embrittlement site. As described above, sufficient hydrogen must be supplied to susceptible microstructure sites in order to activate hydrogen assisted fatigue crack growth. The reduced diffusivity across pearlite bands limits hydrogen supply and decreases fatigue crack growth rates. Any effect of crack-tip branching in retarding FCGR in L-R oriented specimens is amplified by this impeded hydrogen diffusion through layered pearlite. Slightly lower fatigue crack growth rates in the L-C orientation as compared to the $\mathrm{C}-\mathrm{L}$ orientation could be attributed to lower hydrogen diffusivity in the $\mathrm{C}$ direction, as reported in the literature [25]. 
While relative HA-FCG rates for $\mathrm{X} 65$ steel at $\Delta \mathrm{K}<15 \mathrm{MPa} \mathrm{m}^{1 / 2}$ (Fig. 3) are consistent with orientation-dependent hydrogen diffusivity, this relationship between HA-FCG and hydrogen diffusivity is less compelling at $\Delta \mathrm{K}$ levels exceeding $15 \mathrm{MPa} \mathrm{m}^{1 / 2}$. In this higher $\Delta \mathrm{K}$ range, relative differences in HA-FCG rates are less pronounced, e.g., $\left[\mathrm{da} / \mathrm{dN}_{\mathrm{C}-\mathrm{L}}\right] /\left[\mathrm{da} / \mathrm{dN}_{\mathrm{L}-\mathrm{R}}\right]$ in hydrogen gas decreases to approximately 2 , which is similar to $\left[\mathrm{da} / \mathrm{dN}_{\mathrm{C}-\mathrm{L}}\right] /\left[\mathrm{da} / \mathrm{dN}_{\mathrm{L}-\mathrm{R}}\right]$ in air (Table 3). This observation may be related to the cyclic plastic zone size, which defines the volume of crack-tip material subjected to plastic strain accumulation. Since plastic strain accumulation is one of the factors driving crack extension, the cyclic plastic zone size can dictate the crack path. For cracks propagating perpendicular to the banded ferrite-pearlite microstructure, at lower $\Delta \mathrm{K}$ levels the relatively smaller cyclic plastic zone size is more likely to encounter a single microstructure constituent, i.e., ferrite or pearlite. In this case, the crack progresses sequentially through ferrite and pearlite, and da/dN is limited by lower hydrogen diffusivity and associated crack growth rates through pearlite. However, as $\Delta \mathrm{K}$ increases the relatively larger cyclic plastic zone size can envelop both ferrite and pearlite, and the crack can more selectively follow a path through ferrite. This notion that the crack follows a more selective path through ferrite at higher $\Delta \mathrm{K}$ appears to be supported by the crack profile image in Fig. $7 \mathrm{~b}$. The opportunity for the crack to follow a selective path through ferrite at higher $\Delta \mathrm{K}$ nullifies the retarding effect of hydrogen diffusion through pearlite, and HA-FCG rates become less orientation-dependent. The remaining two-fold difference between da/ $/ \mathrm{dN}_{\mathrm{C}-\mathrm{L}}$ and $\mathrm{da} / \mathrm{dN}_{\mathrm{L}-\mathrm{R}}$ at higher $\Delta \mathrm{K}$ reflects crack-tip shielding induced by crack branching in the L-R oriented specimen.

Effects of ferrite-pearlite banding on FCGR are difficult to differentiate from other microstructure anisotropy features such as $\mathrm{MnS}$ stringers aligned with the rolling direction. Cyril et al. [29] observed that a significant reduction in fatigue performance can occur when $\mathrm{MnS}$ stringers are aligned with the crack propagation direction. Hayne [30] found that inclusion shape control through alloying with calcium prevented elongation of inclusions during rolling and diminished orientation dependent fatigue in induction hardened 4140. In previous work [25], hydrogen diffusion was not affected by $\mathrm{MnS}$ stringers at $\mathrm{S}$ levels below $0.01 \%$ and differences in effective hydrogen diffusivity were exclusively attributed to ferrite-pearlite alignment. While it is important to acknowledge that inclusion directionality can influence fatigue crack growth rates and hydrogen diffusion, in the current study sulfur contents were low at $0.001 \%$, which limits $\mathrm{MnS}$ formation, and therefore their effect on diffusion and HA-FCG are negligible.

\section{Conclusions}

Repeatable fatigue crack growth rate relationships, da/dN vs. $\Delta \mathrm{K}$, were measured in $21 \mathrm{MPa}$ hydrogen gas for X65 pipeline steel in three different orientations relative to its banded ferritepearlite microstructure. The following conclusions are drawn from this work:

- In all orientations, fatigue crack growth rates in hydrogen gas were significantly higher than rates in air.

- Fatigue crack growth rates in banded ferrite-pearlite microstructures were a function of orientation in both hydrogen gas and air. In hydrogen gas, fatigue cracks propagating perpendicular to the banded pearlite (i.e., L-R orientation) exhibited growth rates nearly an order of magnitude lower than cracks propagating parallel to the pearlite (i.e., C-L or L-C orientation). 
- Crack branching contributes to orientation-dependent fatigue crack growth rates in both air and hydrogen gas.

- In hydrogen gas, the effect of crack branching in promoting orientation-dependent fatigue crack growth rates appears to be magnified by microstructure-sensitive hydrogen transport. Crack branching and reduced hydrogen transport are more pronounced for fatigue cracks propagating perpendicular to the ferrite-pearlite bands (L-R orientation) and account for the lowest fatigue crack growth rates for this orientation.

\section{Acknowledgments}

The authors acknowledge the Hydrogen Effects on Materials Laboratory team at Sandia National Laboratories, particularly Ken Lee and Jeff Campbell. Metallographic samples were prepared and imaged by Andy Gardea and Ryan Nishimoto. Sandia National Laboratories is a multi-program laboratory managed and operated by Sandia Corporation, for the U.S. Department of Energy's National Nuclear Security Administration under contract DE-AC04-94AL85000. This work was supported by the US Department of Energy Fuel Cell Technologies Office through the Hydrogen Delivery sub-program.

\section{References}

[1] Léon, A. Hydrogen Technology: Mobile and Portable Applications. Springer. 2008. p. 131-134.

[2] European Industrial Gases Association. Hydrogen Transportation Pipelines. In: IGC Doc 121/040E, 2004.

[3] ASME. Hydrogen Standardization Interim Report for Tanks, Piping, and Pipelines. In: STP/PT003, 2005, p. 220.

[4] Cialone HJ, Holbrook JH. Effects of gaseous hydrogen on fatigue crack growth in pipeline steel. Metall Trans A 1985;16:115-122.

[5] San Marchi C., Somerday BP, Nibur KA, Stalheim DG, Boggess T, Jansto S. Fracture and Fatigue of Commercial Grade API Pipeline Steels in Gaseous Hydrogen. In: Proceedings from ASME 2010 Pressure Vessels \& Piping Division, Bellevue, Washington USA, 2010.

[6] Amaro RL, Drexler ES, Slifka AJ. Fatigue crack growth modeling of pipeline steels in high pressure gaseous hydrogen. Int J of Fatigue 2014;62:249-257.

[7] Slifka AJ, Drexler ES, Nanninga NE, Levy YS, McColskey JD, Amaro RL, Stevenson AE. Fatigue crack growth of two pipeline steels in a pressurized hydrogen environment. Corr Sci 2014;78:313-321.

[8] Amaro RL, Rustagi N, Findley KO, Drexler ES, Slifka AJ. Modeling the fatigue crack growth of X100 pipeline steel in gaseous hydrogen. Int J of Fatigue 2014;59:262-271.

[9] Krauss G. Steels: Processing, Structure and Performance. Materials Park, OH: ASM International, 2005.

[10] Mutoh Y, Korda AA, Miyashita Y, Sadasue T. Stress shielding and fatigue crack growth resistance in ferritic-pearlitic steel. Mater Sci and Eng A 2007;468-470:114-119.

[11] Korda AA, Mutoh Y, Miyashita Y, Sadasue T, Mannan SL. In situ observation of fatigue crack retardation in banded ferrite-pearlite microstructure due to crack branching. Scripta Mater 2006;54:1835-1840.

[12] Korda AA, Miyashita Y, Mutoh Y, Sadasue T. Fatigue crack growth behavior in ferritic-pearlitic steels with networked and distributed pearlite structures. Int J of Fatigue 2007;29:1140-1148.

[13] Neeraj T, Gnaeupel-Herold T, Prask H, Ayer R. Residual stresses in girth welds of carbon steel pipes: neutron diffraction analysis. Sci and Tech of Welding and Joining 2011;16:249-253.

[14] ASTM Standard E647-05. Standard Test Method for Measurement of Fatigue Crack Growth Rates. ASTM International, West Conshohocken, PA, 2005. 
[15] ASME Standard. B31.12 Hydrogen Piping and Pipelines. New York, NY: ASME, 2011.

[16] Somerday BP, Sofronis P, Nibur KA, San Marchi C, Kirchheim R. Elucidating the variables affecting accelerated fatigue crack growth of steels in hydrogen gas with low oxygen concentrations. Acta Mat 2013;61:6153-6170.

[17] ASTM Standard E647-11. Standard Test Method for Measurement of Fatigue Crack Growth Rates. ASTM International, West Conshohocken, PA, 2011.

[18] Slifka AJ, Drexler ES, Amaro RL, Lauria DS, Hayden LE, Stalheim DG, Chen Y. Summary of an ASME/DOT Project on Measurements of Fatigue Crack Growth Rate of Pipeline Steels PVP2014-2893. In: ASME 2014 Pressure Vessels \& Piping Division Conference Proceedings. 2014. Anaheim, California USA: ASME Press.

[19] Drexler ES, Slifka AJ, Amaro RL, Lauria DS. Fatigue Crack Growth Rate of Pipeline Steels in Pressurized Hydrogen Gas: Comparions of Cyclic Loading Rates. In: Steely Hydrogen Conference Proceedings. 2014. Ghent, Belgium.

[20] San Marchi C, Somerday B, Nibur K, Stalheim D, Boggess T, Jansto S. Fracture and Fatigue of Commerical Grade API Pipeline Steels in Gaseous Hydrogen. In: Proceedings of the ASME 2010 Pressure Vessels \& Piping Division / K-PVP Conference, PVP2010-25825, 2010. Bellevue, WA, USA.

[21] Stalheim D, Boggess T, San Marchi C, Jansto S, Somerday B, Muralidharan G. Microstructure and Mechanical Property Performance of Commerical Grade API Pipeline Steels in High Pressure Gaseous Hydrogen. In: Proceedings of IPC 2010, IPC2010-31301, 2010. Calgary, Alberta, Canada.

[22] Hussain K, De Los Rios RR. Microstructural effect on tensile and fatigue behaviour of C-Mn steel. J of Mater Sci 1997;32:3565-3569.

[23] Moro I, Briottet L, Lemoine P, Andrieu E, Blanc C, Odemer G. Hydrogen embrittlement susceptibility of a high strength steel X80. Mater Sci and Eng A 2010;527:7252-7260.

[24] San Marchi C, Somerday BP, Nibur KA, Stalheim DG, Boggess T, Jansto S. Fracture Resistance and Fatigue Crack Growth of X80 Pipeline Steel in Gaseous Hydrogen. In: ASME Pressure Vessls \& Piping Division Proceedings 2011. Baltimore, Maryland USA.

[25] Tau L, Chan SLI. Effects of ferrite/pearlite alignment on the hydrogen permeation in a AISI 4130 steel. Mater Letters 1996;29:143-147.

[26] Lee HL, Lap-Ip Chan S. Hydrogen embrittlement of AISI 4130 steel with an alternate ferrite/pearlite banded structure. Mater Sci and Eng A 1991;142:193-201.

[27] Cialone HJ, Holbrook JH. Microstructure and fractographic features of hydrogen-accelerated fatigue crack growth in steels. Micro Sci 1987;14:407-422.

[28] Anderson TL. Fracture Mechanics: Fundamentals and Applications, $3^{\text {rd }}$ Ed; Taylor and Francis Group, 2005.

[29] Cyril N, Fatemi A, Cryderman B. Effects of Sulfur Level and Anisotropy of Sulfide Inclusions on Tensile, Impact, and Fatigue Properties of SAE 4140 Steel. SAE Int J Mater Manuf 2009;1:218227.

[30] Hayne ML, Anderson PI, Findley KO, Van Tyne CJ. Effect of Microstructural Banding on the Fatigue Behavior of Induction-Hardened 4140 Steel. Metall and Mater Trans A 2013;44:34283433. 